\title{
Influence of limestone powder dosage on performance of cement mortar
}

\author{
Meiyan Hang ${ }^{1, a}$,Lan $\mathrm{Lu}^{2, \mathrm{~b}}$ and Meng $\mathrm{GaO}^{3, \mathrm{c}}$ \\ 1.Inner Mongolia University of Science and Technology, Baotou 014010 \\ 2.Inner Mongolia University of Science and Technology, Baotou 014010 \\ 3.Baotou Steel Deer Building Materials Co, Ltd, 014010 \\ ahangmeiyan64@126.com,b15848211103@163.com,changmeiyan64@126.com
}

\begin{abstract}
Key words: Limestone dust; Strength; Sulfate resistance
Abstract: The effect of the amount of limestone powder (particle size less than $0.08 \mathrm{~mm}$ ) on the properties of cement mortar was studied by substituting the proportion of cement.Results show:The amount of limestone powder is less than $12 \%$, it has the function of reducing water and not reducing mortar strength; others, the addition of limestone powder can effectively improve the shrinkage performance and sulfate resistance of cement mortar,it is indicated that limestone powder has certain activity, not inert material.The study provides a reliable technical basis for the use of discarded limestone powders in the future.
\end{abstract}

\section{Introduction}

With the increasing of the concrete dosage, the natural sandstone resources in many places are scarce, and the quarry which uses limestone to make artificial sand and gravel is appeared. In the process of producing artificial sand and gravel, Produced a lot of particle size less than $0.08 \mathrm{~mm}$ of dust particles, that is, limestone dust, the specification is called mud.The mixture of limestone dust in the artificial sand (the mud in the specification) will have unpredictable effects on the performance of the concrete.It is very important to study how to make effective use of particle diameter less than $0.08 \mathrm{~mm}$ in cement or concrete, that will be of great significance to the sustainable development of concrete industry.In order to study the effect of limestone dust on the properties of cement mortar, the relative test of limestone dust is used to substitute cement.

\section{Raw Materials and Test Methods}

\subsection{Raw materials}

\section{Cement: P.O42.5 cement}

Sand: Standard sand

Limestone dust: Baotou local limestone ground, water demand ratio of $96 \%$, chemical constituents see table 1 .

Water: ordinary tap.

Immersion solution: The concentration of 5\% 10\% sulfate solution, sulfate for industrial use anhydrous sodium sulfate.

Table 1 Chemical constituents of limestone dusts(\%)

\begin{tabular}{lllllllll}
\hline $\mathrm{CaO}$ & $\mathrm{MgO}$ & $\mathrm{Fe} 2 \mathrm{O} 3$ & $\mathrm{Al} 2 \mathrm{O} 3$ & $\mathrm{SiO} 2$ & $\mathrm{SO} 3$ & Burn loss & $\begin{array}{l}\text { Fineness }(0.045 \mathrm{~mm} \\
\text { sieve })\end{array}$ & MB value \\
\hline 51.62 & 4.32 & 0.24 & 0.76 & 7.97 & 0.19 & 42.1 & 1.70 & 0.5 \\
\hline
\end{tabular}

\subsection{Test methods}

\subsubsection{Fluidity of cement mortar}

The rubber sand was prepared by the mixture ratio show in table 2, and the test was carried out according to the GB/T2419-2005 《Test method for fluidity of cement mortar》.

\subsubsection{Cement mortar strength}

According to the mixture ratio give in table 2, the rubber specimens were prepared, Conservation by the GB/T17671 -1999 《Method of testing cements-Determination of strength》,determination the Strength and Flexural Strength of different age period. 


\subsubsection{Shrinkage rate of cement mortar}

According to the proportion show in table 2, sand specimen of size $25 \mathrm{~mm} \times 25 \mathrm{~mm} x 280 \mathrm{~mm}$ was prepared according to JC/T 603-2004 《cement mortar dry shrinkage test method》.After the specimen molding $24 \mathrm{~h}$, measure the initial length, and put $(20 \pm 2){ }^{\circ} \mathrm{C}$ water for curing, after $7 \mathrm{~d}$ again measured the length of the specimen, and the specimen in the air to maintain, respectively test $(7+7) \mathrm{d},(7+21) \mathrm{d}$ and $(7+49) \mathrm{d}$ The length of the specimen.

\subsubsection{Resistance of cement mortar to sulfate erosion}

According to table 2 , the size of the rubber-sand specimens is $40 \mathrm{mmx} 40 \mathrm{mmx} 160 \mathrm{~mm}$, molding $24 \mathrm{~h}$ after demoulding, put into the standard curing room maintenance, testing the strength of $3 \mathrm{~d}$ and $28 \mathrm{~d}$. After reaching the $28 \mathrm{~d}$ aging, the specimen was soaked in the sodium sulfate solution of $5 \% \sim 10 \%$ concentration, the soaking time was $7 \mathrm{~d}, 14 \mathrm{~d}, 28 \mathrm{~d}, 56 \mathrm{~d}$ and $90 \mathrm{~d}$. Later the strength was tested. The sodium sulfate solution is changed once in a month.

Table 2 Cement mortar test mix ratio

\begin{tabular}{llllll}
\hline Number & Cement/g & Limestone dust/g & Replace rate/\% & Sand/g & Water/g \\
\hline LP-0 & 450 & 0 & 0 & 1350 & 225 \\
LP-4 & 432 & 18 & 4 & 1350 & 225 \\
LP-6 & 423 & 27 & 6 & 1350 & 225 \\
LP-8 & 414 & 36 & 8 & 1350 & 225 \\
LP-10 & 405 & 45 & 10 & 1350 & 225 \\
LP-12 & 394 & 54 & 12 & 1350 & 225 \\
LP-14 & 387 & 63 & 14 & 1350 & 225 \\
LP-18 & 369 & 81 & 18 & 1350 & 225 \\
LP-22 & 351 & 99 & 22 & 1350 & 225 \\
LP-26 & 333 & 117 & 26 & 1350 & 225 \\
LP-30 & 315 & 135 & 30 & 1350 & 225 \\
\hline
\end{tabular}

\section{Effect of limestone dust on the properties of cement mortar}

\subsection{Effect of limestone dust on the fluidity of cement mortar}

The effect of limestone dust on the fluidity of cement mortar was studied, as shown in Fig. 1.

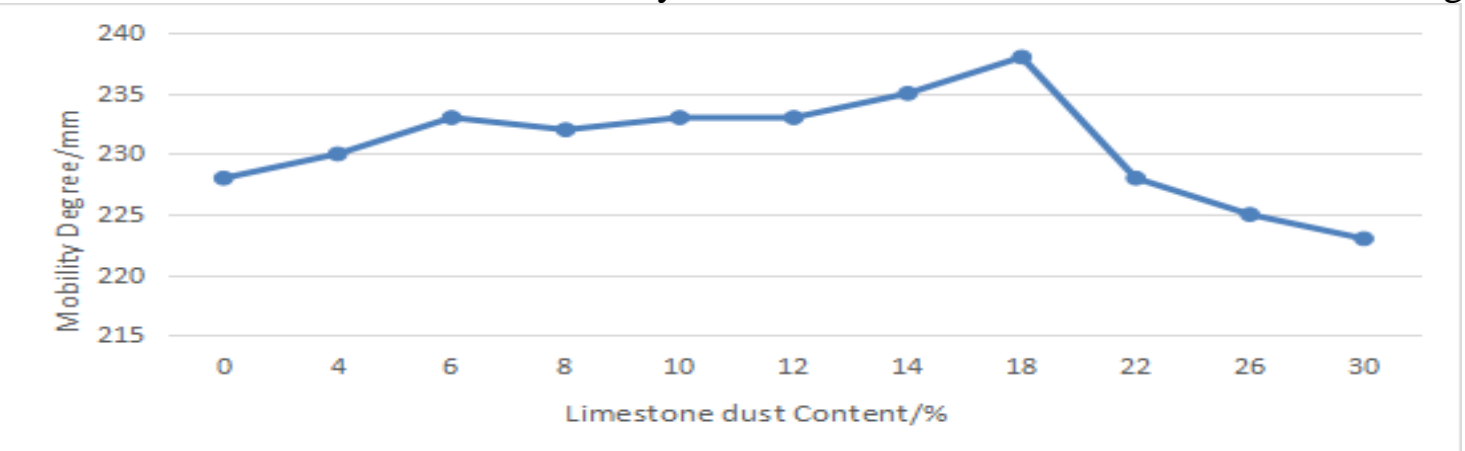

Fig. 1 Effect of limestone dust on the fluidity of cement mortar

As shown in Fig. 1, for 18\% limestone dust, the sand flow is between 230 238mm. As the amount of admixture continues to increase, the fluidity of mortar starts to decrease, which is less than the benchmark mobility. It shows that limestone dust has a certain water reduction effect, the water reducing degree is related to the amount of limestone dust, and the water reducing effect of limestone dust increases and decreases with the increase of mixing component. Due to the small size of limestone dust, adding cement improves the particle size of the powder, dense limestone dust particles get dispersed between the cement particles, which played the role of dispersants ${ }^{[1]}$. The fluidity of cement slurry has improved; when limestone dust exceeds a certain amount, the fluidity of slurry decreases gradually, which is because the specific surface area of powdery material is larger, the water consumption of the surface is increased, and the free moisture decreases, causing the pulp thickening. 


\subsection{Effect of limestone dust on the strength of cement mortar}

The effect of limestone dust on the strength of cement mortar was studied, and the results are shown in Fig. 2 and Figure 3.

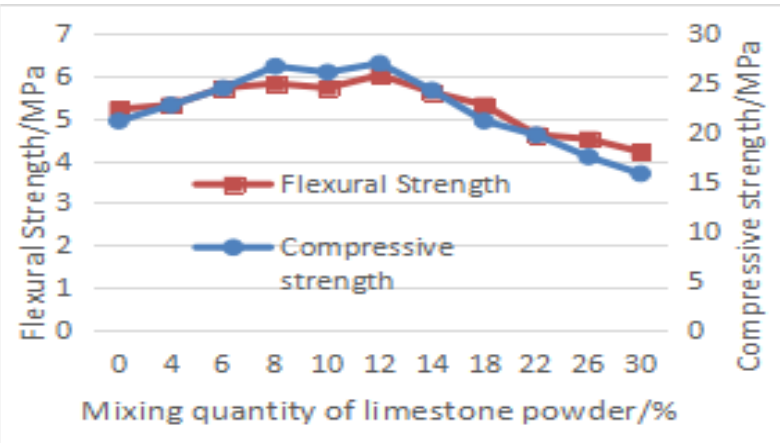

Fig. 2 The cement mortar's strength on3d and 28d under different dosage of limestone Powder

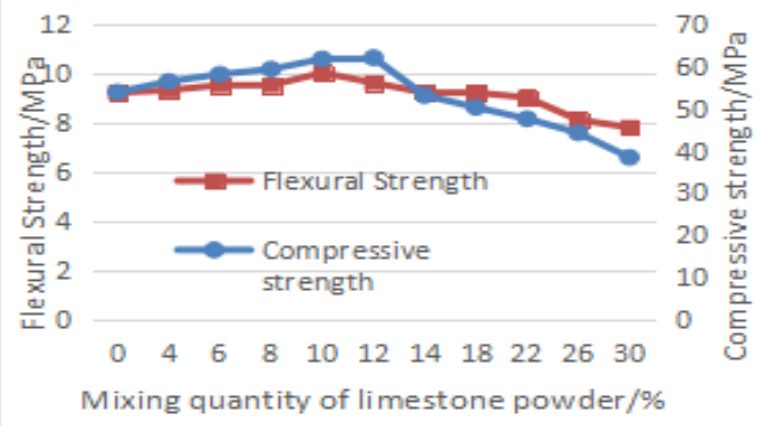

Fig. 3 The cement mortar's flexural strength on $3 \mathrm{~d}$ and $28 \mathrm{~d}$ under different dosage of limestone Powder

Fig. 2 and Fig. 3 show that the strength of cement mortar was highest at $12 \%$ limestone dust, which was larger than that of the benchmark mortar, and the intensity began to decrease on both sides. The decrease was increasing more for larger percentages of limestone powder. The main reasons are : : (1) As the percentage of limestone dust is increased, the cement slurry voids are filled with fine particles giving a dense pulp structure, and when a small amount of hydration products can be firmly bonded to the non-hydration particles, the pulp strength becomes higher.(2) Limestone dust has accelerated hydration effect; the appropriate dosage of limestone dust acts as a $\mathrm{C}-\mathrm{S}-\mathrm{H}$ nucleation matrix giving rise to accelerated hydration of cement ${ }^{[2]}$. With the increase of the amount of limestone dust, a large number of fine limestone dust particles need more hydration products adhesion, and the gel products are limited, so that the slurry strength decreases.

\subsection{Effect of limestone dust on shrinkage properties of mortar}

The volume changes in the hydration process of the cement mortar specimens , and the shrinkage rate of cement mortar specimens is used to evaluate the volumetric stability of specimens. The test results are shown in table 3.

Table 3 results show that Limestone dust equivalent to replace the cement, the dosage is less than $30 \%$, with the increase in dosage, cement mortar at all ages shrinkage value gradually reduced.The main reason is: Compared with cement particles, the surface of limestone dust is relatively smooth, which can make the cement slurry in the same water-cement ratio more free, thus reducing the shrinkage.In addition, The $\mathrm{CaCO} 3$ in limestone dust particles can react with $\mathrm{C} 3 \mathrm{~A}$ in the cement granules, producing the expansive hydration product $\mathrm{C} 3 \mathrm{~A} \cdot \mathrm{CaCO} 3 \cdot 11 \mathrm{H} 2 \mathrm{O}$ to compensate for shrinkage, The micro-aggregate effect of limestone dust fills the void inside the cement stone, improves the pore structure and improves the shrinkage property of cement mortar[3]. 
Table 3 Effect of limestone dust on shrinkage properties of cement mortar

\begin{tabular}{llllll}
\hline Number & $\begin{array}{l}\text { Limestone } \\
\text { admixture/\% }\end{array}$ & Powder & \multicolumn{4}{l}{ Shrinkage Rate/\% } & & \\
\cline { 3 - 6 } & & $7 \mathrm{~d}$ & $(7+7) \mathrm{d}$ & $(7+21) \mathrm{d}$ & $(7+49) \mathrm{d}$ \\
\hline LP-0 & 0 & +0.0018 & -0.019 & -0.0535 & -0.0746 \\
LP-6 & 6 & +0.0032 & -0.016 & -0.04785 & -0.071 \\
LP-14 & 14 & +0.0030 & -0.011 & -0.0459 & -0.0693 \\
LP-20 & 20 & +0.0029 & -0.012 & -0.0434 & -0.069 \\
LP-30 & 30 & +0.0046 & -0.015 & -0.0484 & -0.0718 \\
\hline
\end{tabular}

Note: "+" denotes expansion, "-" means contraction. "(7+7) d" means that the cement mortar is maintained in the water for $7 \mathrm{~d}$ and then transferred to the dry air to maintain the prescribed age and other analogies.

\subsection{Effect of limestone dust on the sulfate-resistant properties of cement mortar}

The experimental results showed that the compressive and flexural strength of cement mortar in sulfate environment changed with the time of corrosion, and the concrete test result was shown in table 4.

Table 4 effect of limestone dust on sulfate erosion resistance of cement mortar

\begin{tabular}{|c|c|c|c|c|c|c|c|}
\hline $\begin{array}{l}\text { Test } \\
\text { number }\end{array}$ & $\begin{array}{l}\text { Limestone } \\
\text { Powder } \\
\text { admixture/ } \\
\%\end{array}$ & $\begin{array}{l}\text { Standard } \\
\text { raising } 3 \mathrm{~d} \\
\text { flexural } \\
\text { /compressive } \\
\text { strength/MP } \\
\text { a }\end{array}$ & $\begin{array}{l}\text { Standard } \\
\text { raising } \\
\text { 28d flexural } \\
\text { /compressiv } \\
\text { e } \\
\text { strength/MP } \\
\text { a }\end{array}$ & $\begin{array}{l}\text { Soaking7d } \\
\text { flexural/com } \\
\text { pressive } \\
\text { strength } \\
/ \mathrm{MPa} \text { in } \\
\mathrm{Na}_{2} \mathrm{SO}_{4} \\
\text { solution }\end{array}$ & $\begin{array}{l}\text { Soaking28d } \\
\text { flexural/com } \\
\text { pressive } \\
\text { strength/ } \\
\mathrm{MPa} \text { in } \\
\mathrm{Na}_{2} \mathrm{SO}_{4} \\
\text { solution }\end{array}$ & $\begin{array}{l}\text { Soaking28d } \\
\text { flexural/com } \\
\text { pressive } \\
\text { strength/ } \\
\mathrm{MPa} \text { in } \\
\mathrm{Na}_{2} \mathrm{SO}_{4} \\
\text { solution }\end{array}$ & $\begin{array}{l}\text { Soaking90d } \\
\text { flexural/com } \\
\text { pressive } \\
\text { strength } \\
/ \mathrm{MPa} \text { in } \\
\mathrm{Na}_{2} \mathrm{SO}_{4} \\
\text { solution }\end{array}$ \\
\hline LP-0 & 0 & $5.1 / 22.68$ & $9.7 / 51.72$ & $10.5 / 53.33$ & $10.9 / 61.99$ & $11.4 / 62.75$ & $11.2 / 51.4$ \\
\hline LP-6 & 6 & $5.0 / 21.06$ & $8.6 / 43.96$ & $10.2 / 47.29$ & $10.5 / 52.29$ & $11.2 / 59.58$ & $11.0 / 55.12$ \\
\hline LP-14 & 14 & $4.3 / 19.25$ & $8.7 / 41.88$ & $9.6 / 44.79$ & $10.6 / 45.27$ & $11.0 / 48.13$ & $10.0 / 45.14$ \\
\hline LP-20 & 20 & $3.9 / 15.99$ & $8.1 / 39.69$ & $8.5 / 40.83$ & $9.5 / 45.09$ & $10.3 / 48.06$ & $9.8 / 45.00$ \\
\hline LP-30 & 30 & $4.3 / 14.11$ & $7.4 / 34.03$ & $8.0 / 36.94$ & $8.6 / 40.01$ & $9.8 / 40.00$ & $9.6 / 36.74$ \\
\hline
\end{tabular}

The test results show that the strength of cement mortar is increased when the specimen is immersed in 56d, although the strength of cement mortar mixed with limestone dust is smaller than that of base sand, its growth range is larger than that of base sand.When soaking more than 56d, the strength of cement mortar began to decline, and the strength loss rate of cement mortar with limestone dust is obviously lower than that of base sand. It is shown that the limestone dust mortar has better corrosion resistance than the reference sand in the short term sulfate environment. The damage of sulfate to cement mortar is due to the infiltration of sulfate in cement mortar with $\mathrm{C} 3 \mathrm{~A}$ and its hydration product $\mathrm{Ca}(\mathrm{OH}) 2$ reaction to produce gypsum ,resulting in the expansion of cement mortar volume, with the increase of time, the cement mortar has been seriously damaged.The sand with limestone dust has more corrosion resistance than the base rubber sand, This is because limestone dust has physical tight filling and chemical activation, can promote the hydration of calcium silicate, increase cement hydration speed, and make a single sulfur hydrated calcium aluminate transformation into a stable single carbon hydrated calcium aluminate [4-5], so that limestone-doped cement stone dust than pure water clay structure more dense, high strength.

\section{Conclusion}

(1) Adding limestone dust to the fluidity of cement mortar has some improvement effect, with the increase of limestone dust content, the fluidity of cement mortar decreases gradually.

(2) Limestone dust content is less than $12 \%$, the early and late strength of cement mortar has increased, indicating that limestone dust does not belong to the category of mud, not inert materials.

(3) Mixing limestone dust can reduce the shrinkage rate of cement mortar at various ages, improve the shrinkage performance of cement mortar, and the shrinkage rate decreases with the increase of mixing quantity when the mixing quantity is less than $30 \%$.

(4) in the environment of sulfate erosion, with the increase of corrosion time, the strength of specimens decreased after the first increase, lime-doped limestone dust cement mortar strength loss 
rate than the benchmark sand small, indicating that mixing the amount of limestone dust can improve the cement mortar of the resistance to sulfate erosion.

\section{Reference}

[1] Pan Mingnan, Duan Meiyun, Zhang Guixiang. Effect of ultrafine limestone powder on the performance of high strength and high performance concrete [J]. Shanxi Construction, 2008, 34 (30): 187-188.

[2] Liu counted China. Effect of limestone powder on hydration characteristics of composite cementitious materials [d]. Postdoctoral research report of Tsinghua University. Beijing: Tsinghua University, 2007.[3] Li Honghui, Pu Chengzhong, Yao Jianzhong. Effect of limestone powder on shrinkage properties of concrete [J]. Shanxi Construction, 2009, 35 (26): 144-146.

[4] Deng Dehua, Shaojia, Yuan strong, etc. Effect of limestone powder on sulphate erosion resistance of cement-based materials and its mechanism [J]. Journal of Silicate, 2006, 34 (10): 1243-1245.

[5] Yan Junwei, Xing Jie, Li Jie, etc. Summarization of limestone powder concrete and its sulfate erosion characteristics [J]. Concrete, 2011 (8): 79-84. 